\title{
Help from an unusual source
}

\section{Tokyo}

HigH-TECHNOLOGY military equipment has found an unexpected role in helping scientists to study the erupting volcano Mount Unzen, which discharged again Sunday, destroying about 100 homes and a school.

After a pyroclastic flow of hot volcanic gas and ash swept down the slope of Unzen on 3 June, killing more than 40 people, a troop of about 600 self-defence force personnel were sent to the area, initially to search for survivors and bodies in the disaster zone. But soon after arrival, the army set up a variety of devices to detect pyroclastic flows from the volcano, and the self-defence forces now play a vital role in the scientific monitoring of Unzen.

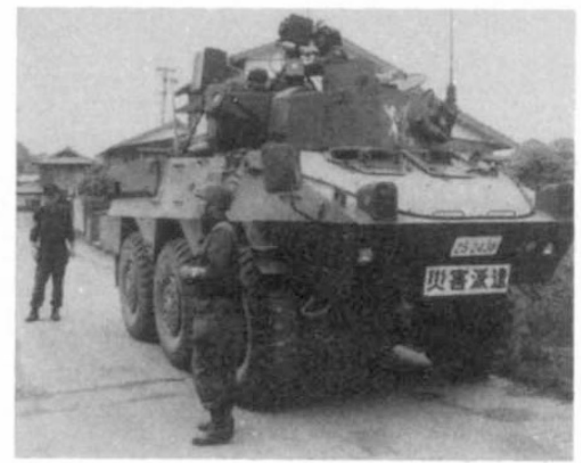

Tanks for the help

The expensive equipment deployed by the troops far outshines the facilities at nearby government-run observatories. For example, the latest high-technology Doppler radar, designed for detecting attacking jet fighters and missiles, has been trained on the erupting volcano to pick up the high-speed pyroclastic flows, which at any time could come rushing down Mount Unzen at speeds of hundreds of kilometres an hour.

In addition, about ten soldiers are permanently deployed at the local Shimabara
Earthquake and Volcano Observatory of Kyushu University. They maintain a 24hour watch for possible seismic activity associated with the volcanic eruption and are in constant touch with military headquarters to report any evidence of pending volcanic activity. The soldiers have become so expert in their interpretation of seismographs in the past three months that they sometimes substitute for the limited number of scientists at the observatory during the small hours of the night. Kazuya Ohta, director of the observatory, says he would welcome the soldiers as assistant researchers any time.

The military also frequently flies scientists over the volcano in self-defence helicopters to check the condition of the huge lava dome that sits precariously on the edge of the volcano's crater. And soldiers in Shimabara, who outnumber scientists by about ten to one, occasionally venture into the declared danger zone at the foot of the volcano in their armoured vehicles and tanks to collect samples for the researchers.

Unzen provides a rare opportunity for Japan's volcanologists to watch pyroclastic flows in action. The observations should yield valuable data for the interpretation of such flows in the geological record.

The lava dome of Unzen continues to grow. In the past few weeks, pyroclastic flows have headed in new directions, forcing the evacuation of another 1,000 or so people and bringing the total number of evacuees to more than 10,000 . There is no sign that these people, many of whom have been without a home for more than three months, can return to their former homes in the near future. Even with the presence of the Japanese military, the danger of a 'surprise attack' by the volcano remains too great.

David Swinbanks

\section{New Indian satellite is up}

\section{New Delhi}

INDIA's efforts to hamess space technology for managing its natural resources took a leap forward on 29 August when its second remote-sensing satellite, IRS-1B, went into orbit after a successful launch from Baikonur Cosmodrome in central Asia. The launch took place as scheduled despite fears in India that it might be postponed because of internal problems in the Soviet Union following the abortive coup.

Designed and built by the Indian Space Research Organisation (ISRO) in Bangalore, the $980-\mathrm{kg}$ polar orbiting satellite is identical to its predecessor IRS-1A, launched in March 1988. IRS-1A has mapped all of India for ground water potential, and has also made a soil map, a land use map and a forest map. The launch of IRS-1B will double the country's capacity for data acquisition. Together, the two spacecraft will be able to cover the entire subcontinent once every 12 days as compared to 22 days by IRS-1A alone. ISRO also hopes to sell the images to other countries in the region.

ISRO says its future remote-sensing satellites IRS-1C and IRS-1D will have better resolution, stereo viewing, on-board recording and more frequent revisit capabilities. These are planned to be launched in 1993 and 1996.

\section{Chasing the source of radioactive steel}

\section{New Delhi}

INDIA's Atomic Energy Commission is investigating the circumstances that resulted in radioactive contamination of steel products exported to the United States by a private company in Calcutta. The inquiry follows last week's discovery by the US Nuclear Regulatory Commission (NRC) that the products contained traces of radioactive cobalt- 60 .

The steel products included several thousand tons of chain links for fencing, gate bars and truss rods. They were imported from Katia Steel Rolling Mills in Calcutta by Master Halco Inc., a US distributor in La Habra. California, and had been redistributed to retailers and wholesalers throughout the United States. According to the NRC, 5 per cent of the chain links tested were slightly radioactive. Further shipments from India have been halted, and the NRC has contacted the Indian government to ensure that it is aware of the problem and to determine the scope and source of contamination.

The Bhabha Atomic Research Centre (BARC) in Bombay is the only place in India that produces cobalt-60 in large amounts for industrial, medical and agricultural applications. But BARC has not supplied cobalt-60 sources to any steel rolling mills in the country and the chairman of the atomic energy commission, P.K. Iyengar, ruled out BARC-made cobalt 60 as being the source of contamination.

Iyengar says the cobalt-60 could have originated outside India because the Calcutta company was making steel by mixing locally available as well as imported scrap iron. This practice is common among steel rolling mills in India because imported scrap is cheaper. "Our suspicion is that the imported scrap used in steel-making might have been contaminated with cobalt-60," Iyengar said. Most blast furnaces abroad - not in India use cobalt-60 in detectors to check the lining of the furnace for erosion. According to Iyengar, if the cobalt source accidentally falls inside the furnace, all the iron will be contaminated. The Atomic Energy Commission team will analyse the samples of scrap iron in the possession of the Calcutta company to find out whether or not the imported scrap is contaminated.

Some 25 years ago, aluminium pipes sold in 'thieves' bazaars' in Bombay were found to be radioactive. Investigations revealed that the pipes had been fashioned out of material removed from a radioactive waste dump in one of the BARC facilities. But BARC sources insist that present security arrangements are so tight that no waste material can escape from the grounds.
K.S. Jayaraman 